\title{
Upper Airway Assessment and Responses During Mechanically Assisted Cough
}

\author{
Tiina M Andersen, Brit Hov, Thomas Halvorsen, Ola Drange Røksund, and Maria Vollsæter
}

\author{
Introduction \\ Theoretical Background \\ The Laryngeal Role in the Healthy Individual \\ Cough Is Not Cough Without a Functioning Larynx \\ The Dysfunctional Larynx \\ Literature Review \\ CT Scanning \\ TFL \\ TFL and Videofluoroscopy \\ Air Flow Curve Registration \\ Laryngeal Models \\ Discussion \\ Summary of the Findings \\ Where Should We Go From Here? \\ Clinical Implications \\ Individualizing MI-E Treatment \\ Effect Outcomes for Airway Clearance \\ Summary
}

\begin{abstract}
When the ability to cough is impaired, secretion clearance may be assisted and augmented with mechanical insufflation-exsufflation (MI-E). In some individuals, the efficacy of MI-E may be hampered by counterproductive upper airway reactions, where the airways close in response to positive pressures. To fully utilize the therapeutic potential inherent in the MI-E technology, we need a better understanding of the pathophysiology behind these untoward reactions. There is increasing interest in monitoring and measuring upper airway responses to MI-E and how such information can be used to optimize MI-E settings. The purpose of this narrative review is to increase the theoretical understanding of the larynx as a respiratory organ, summarize the current literature in the area, and provide insight into how this knowledge can affect current clinical practice. Key words: mechanical insufflation-exsufflation; cough augmentation; upper airways; larynx; laryngoscopy; assessment; neuromuscular disease; motor neuron disease; bulbar paresis. [Respir Care 2021;66(7):1196-1213. (C) 2021 Daedalus Enterprises]
\end{abstract}

\section{Introduction}

Clearing the airways for secretions is vital to sustain a healthy respiratory system. The process entails shearing of the secretions from the airway walls and then propelling the debris toward the larger airways. Secretion relocation depends on air flow velocity as well as the shape and cross-sectional area of the airway. ${ }^{1,2}$ Cough is the final part of airway secretion clearance, and the mechanism by which the central airways are cleared. ${ }^{1}$

Neuromuscular disorders (NMDs) may cause muscular weakness leading to weak cough, inability to clear the 
airways sufficiently, accumulation of secretion, and complications like dyspnea and pneumonia. Mechanical insufflation-exsufflation (MI-E) is used to assist cough in individuals with NMD. The device simulates normal cough by (1) applying a positive pressure leading to insufflation and lung expansion, followed by (2) a rapid switch to a negative pressure leading to an exsufflation that sucks air and consequently secretions out of the airways. MI-E is considered safe and effective ${ }^{3-10}$ and, in conjunction with noninvasive ventilation (NIV), may delay or prevent intubation or tracheostomy. ${ }^{11-13}$ On the basis of successful experiences in individuals with NMD, MI-E treatment has also been applied in subjects with impaired cough for other reasons, such as in critically ill individuals under intensive care ${ }^{14-16}$ and in persons with other neurologic disorders like cerebral palsy, ${ }^{17-20}$ neuropathy, multiple sclerosis, Parkinson disease, ${ }^{19}$ myotonic dystrophy, ${ }^{19,21}$ and Kennedy disease. ${ }^{22}$

MI-E therapy applied noninvasively (via a face mask) is not effective in all patients. Challenging individuals often share symptoms of disturbed laryngeal function and/or bulbar symptoms. The noninvasive use of MI-E has proven difficult in individuals with bulbar muscular dysfunction, such as amyotrophic lateral sclerosis (ALS), because poor laryngeal control appears to obstruct air flow. ${ }^{23-29}$ These observations have changed the current landscape of MI-E research. An understanding of upper airway function, especially the complexity of larynx as an organ, is necessary to make a difference. Numerous groups now engage in projects aiming to monitor and prevent counterproductive upper airway responses and thus increase the knowledge on optimal adjustments of the MI-E settings.

Dr Andersen, Dr Vollsæter, and Ms Hov are affiliated with the Thoracic
Department, Norwegian Advisory Unit on Home Mechanical Ventilation,
Haukeland University Hospital, Bergen, Norway. Dr Andersen is affiliated
with the Department of Physiotherapy, Haukeland University Hospital,
Bergen, Norway. Drs Halvorsen, Røksund, and Vollsæter are affiliated
with the Department of Pediatrics, Haukeland University Hospital,
Bergen, Norway. Drs Andersen and Røksund are affiliated with The
Faculty of Health and Social Sciences, Western Norway University of
Applied Sciences, Bergen, Norway. Drs Halvorsen and Vollsæter are
affiliated with The Faculty of Medicine, Department of Clinical
Science, University of Bergen, Bergen, Norway. Ms Hov is affiliated
with the Division of Paediatric and Adolescent Medicine, Oslo
University Hospital, Oslo, Norway. Ms Hov is affiliated with the
Institute of Clinical Medicine, University of Oslo, Oslo, Norway.

Supplementary material related to this paper is available at http://www. rcjournal.com.

The authors have disclosed no conflicts of interest.

Correspondence: Tiina Andersen PT PhD, Norwegian Advisory Unit on Home Mechanical Ventilation, Thoracic Department, Haukeland University Hospital, 5021 Bergen, Norway. E-mail:

tiina.andersen@helse-bergen.no.

DOI: $10.4187 /$ respcare. 08960
We searched for literature on assessment and interpretation of upper airways responses to MI-E. The purpose of this narrative review is to increase the theoretical understanding of larynx as a respiratory organ, to summarize the literature on methods used to assess the upper airways during MI-E and the response patterns that have been described, and to provide insight into how this understanding may affect current practice.

\section{Theoretical Background}

\section{The Laryngeal Role in the Healthy Individual}

The constitution of the upper airways is easy to understand from an evolutionary point of view. The human evolution from water to dry land existence altered the pulmonary development by allowing gas exchange directly from the air..$^{30}$ The lungs became integrated within the thoracic cage, including a complex "gateway function" centrally positioned in the upper airways, guarding the entrance to the lower airways and protecting the delicate distal gas exchange surfaces from foreign bodies, injury, and dehydration. ${ }^{31}$ Whereas the laryngeal function in primitive species is primarily protective, development of the human larynx led to an abduction mechanism better facilitating ventilation. Further, a demand for phonation required the gateway to be able to perform fine-tuned rapid movements of narrowing and opening, ${ }^{32}$ and thus the laryngeal inlet became a potential major point of air flow resistance within the respiratory tract. ${ }^{33-35}$ This gives an upper airway that crosses the upper gastrointestinal tract, with the larynx centrally positioned in an intersection that must integrate the primitive protective laryngeal function, ${ }^{36}$ the continuous need for ventilation, the transmission of high-volume ventilation during exercise, phonation, swallowing, and cough. ${ }^{31}$

The larynx consists of the hypopharyngeal, supraglottic, glottic, and subglottic areas (Fig. 1) and entails airway mucosa, rigid cartilage skeletons, and ligaments and muscles for adduction and abduction. These structures together create a dynamic cavity with movements at several levels. ${ }^{37}$ Laryngeal muscles are under voluntary as well as reflex control, controlled by sensory-motor reflex responses involving glossopharyngeal, pharyngeal, laryngeal, and tracheobronchial sensory receptors. ${ }^{38}$ The larynx is able to sense gases, liquids, and solids, and it is one of the most highly innervated organs in humans. ${ }^{37,39}$ Innervation is by the internal branch of the superior laryngeal nerve and the recurrent laryngeal nerves, both of which are branches of the vagal nerve. Extrinsic muscles move the larynx as a whole. Intrinsic muscles serve as abductors and stabilizers, all acting more or less directly on the true vocal folds. ${ }^{40}$

The larynx accounts for approximately $25 \%$ of total resistance during mouth breathing at a resting air flow of $\sim$ 


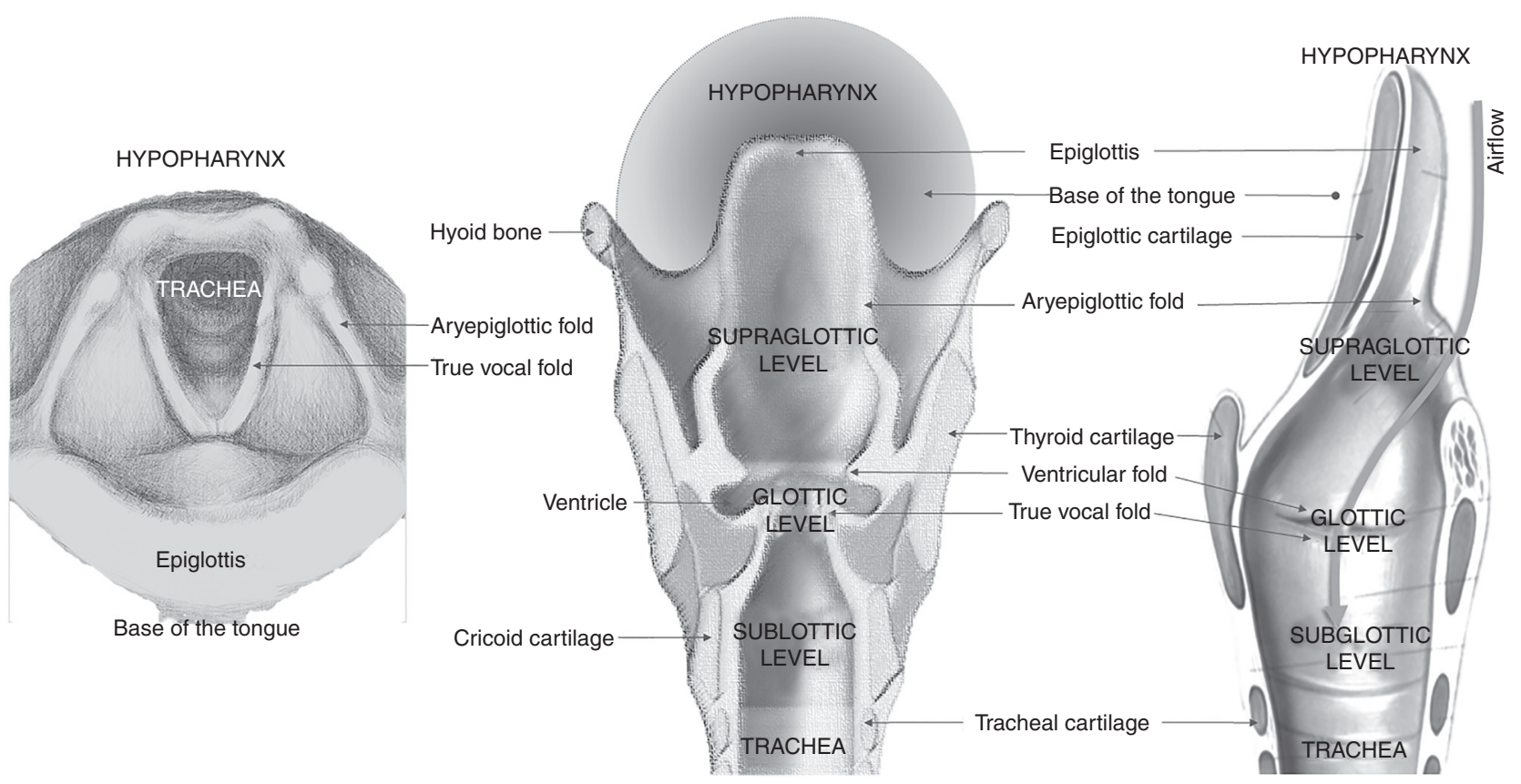

Fig. 1. Superior, posterior, and medial views of the larynx with anatomical landmarks and the laryngeal levels of the hypopharynx, supraglottis, glottis, subglottis, and trachea.

$1 \mathrm{~L} / \mathrm{s} .{ }^{33-35}$ The effort to overcome this resistance requires $12-30 \%$ of the total respiratory work. ${ }^{35}$ At quiet breathing, glottic abduction (opening) is fundamental for free air flow in and out of the lungs at the lowest possible resistance. The glottis widens during inspiration and narrows slightly during expiration. ${ }^{41,42}$ Forced inspiration and expiration, including cough, lead to increased activation of small intrinsic laryngeal muscles. ${ }^{43}$ In light of the importance of laryngeal abduction for proper air flow, it is somewhat unexpected that the larynx has several adductor muscles, but only one abductor muscle. The posterior cricoarytenoid muscle operates in a phasic relationship with the diaphragm, where diaphragmatic vagal stimulation is synchronized with increased posterior cricoarytenoid activity, leading to laryngeal abduction (opening) immediately before diaphragmatic contraction. ${ }^{44}$ The equilibrium of forces between the abductor and adductor muscles determines the size of the laryngeal inlet. This balance can be disturbed by weakness of the abductor muscle or increased activity of the adductor muscles, or vice versa.

Rapid occlusion to prevent foreign bodies entering the airways is a vital responsibility of the larynx, and it has been proposed that adductive movements by nature are dominant to abductive. ${ }^{34}$ Two mechanisms prevent aspiration; reflexive laryngeal closure and a rapid expulsion of inhaled material, usually presenting simultaneously and synchronized. ${ }^{45}$ Stimulation of extremely sensitive supraglottic receptors normally induces complex adductor reflexes that prevent aspiration..$^{44}$ In fact, otolaryngologists use positive air pressure stimulation to provoke laryngeal reflex activities, such as laryngeal closure and swallowing. ${ }^{38,46,47}$ Positive air pressure applied to the laryngeal vestibular mucosa activates nerve afferents in the internal branch of the superior laryngeal nerve, releasing the laryngeal closure reflex. ${ }^{46}$ Positive air pressure to the anterior facial area in the oral cavity activates glossopharyngeal afferents and elicits swallowing. ${ }^{47}$

\section{Cough Is Not Cough Without a Functioning Larynx}

Normal cough proceeds in 3 phases. First, the inspiratory muscles create a negative intrathoracic pressure that leads to air flowing through the upper airways to the lungs that become inflated (deep inspiration phase). Second, the thoracic pressure increases by a rapid closure of the glottis and simultaneous active expiration against this closed valve. In this phase, the laryngeal adductor muscles narrow or close the glottis completely; there is no flow, and the expiration muscles contract forcefully, which allows the subglottic pressure to build up (compression phase). Third is the expulsion phase, which consists of an abrupt opening of the glottis combined with a forceful contraction of the expiratory muscles that leads to the rapid expulsion of air. The air flow might be interrupted by intermittent glottic closures, known as a cough epoch, which consists of consecutive compressive and expulsive phases without intermediate inspirations. Effective cough is a highly dynamic phenomenon, requiring 

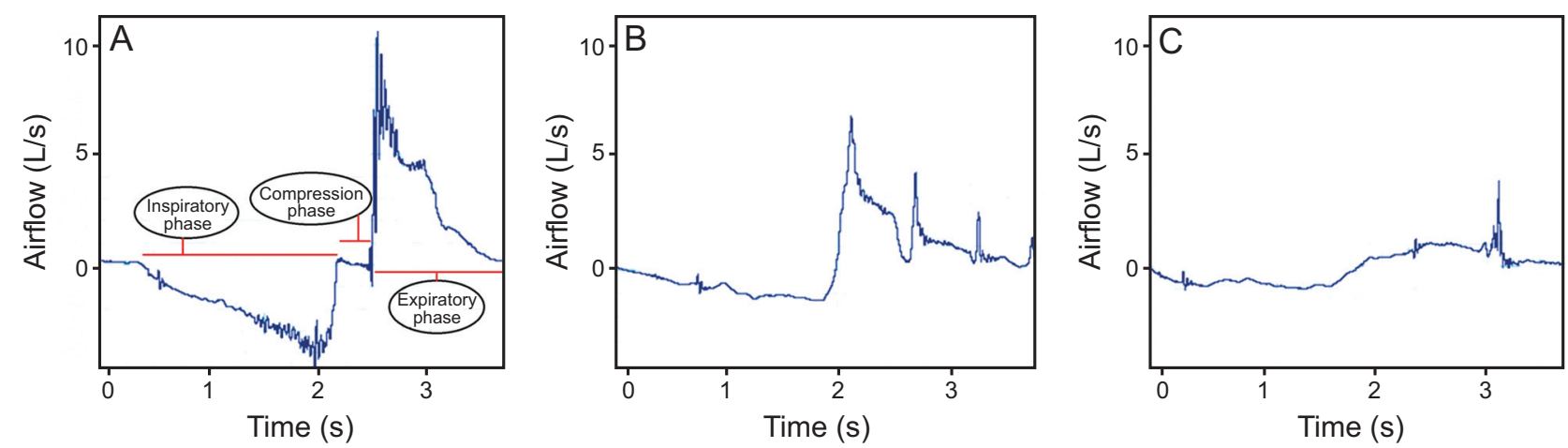

Fig. 2. Voluntary cough spirometry waveform depicting A: cough flow with distinct inspiratory and expiratory parameters in a healthy individual, depicting the 3 primary phases of cough from which objective temporal air flow parameters are computed and aberrant. Cough flow in 2 individuals with amyotrophic lateral sclerosis with B: spinal-onset and C: bulbar-onset disease type. From Reference 68, with permission.

muscular strength and fine-tuned coordination of inspiratory, expiratory, and laryngeal muscles..$^{48,49}$

Without glottic closure and opening, cough is not a cough, but a forced exhalation. When the expiratory muscles contract against a closed glottis, the built up pressure is $\sim 50-100 \%$ greater than that obtained during other forced expiratory maneuvers in which the glottis is open. ${ }^{49}$ Laryngeal closure and opening is related to cough peak flow $(\mathrm{CPF})$, the highest measured air flow spike during cough, appearing immediately after opening of the glottis during the cough cycle.$^{50,51}$ Duration of the cough compression phase has been suggested to primarily manipulate the pace of cough (fast/slow), whereas CPF affects the power of cough (strong/weak). ${ }^{52}$ The threshold for clinically effective secretion removal has been proposed at a CPF of 160-180 L/ min. ${ }^{6,53-56} \mathrm{CPF}$ is the most commonly used measure to determine the effect of spontaneous or assisted cough in persons with NMDs. ${ }^{57}$ This rests on clinical work performed by Barach et $\mathrm{al}^{58}$ in the 1950s. Later research has discussed whether other parameters might be more precise. ${ }^{57}$

\section{The Dysfunctional Larynx}

The protective laryngeal reflexes may disturb voluntary actions and even become counterproductive for other important functions, thereby creating a dysfunctional larynx. ${ }^{31}$ Common respiratory symptoms like shortness of breath and abnormal breath sounds that are caused by laryngeal dysfunction may mimic symptoms of pulmonary diseases. This may confuse respiratory care professionals and lead to laryngeal dysfunction being overlooked.

In the critically ill, the larynx is commonly dysfunctional following endotracheal extubation, possibly due to the rigid endotracheal tube impairing the reflex response patterns of the extremely sensitive laryngeal area. ${ }^{59}$ Chronic neurological diseases, such as ALS, spinal muscular atrophy, cerebral palsy, and Parkinson disease, may affect the function of bulbar innervated muscles. Malfunctioning sensory afferent nerves and abnormal reflex responses impair muscle coordination, causing weakness or spasms. ${ }^{39,60-66}$ This disturbs speech, cough, and swallowing. ${ }^{67}$

In persons with ALS and bulbar involvement, MI-E may fail to increase CPF. ${ }^{25-29}$ Tabor-Gray et al ${ }^{68}$ explored voluntary cough in individuals with ALS, stating that subjects with ALS cough differently compared to healthy individuals, and that both inspiratory and expiratory air flows are affected, in that the inspiratory phase is prolonged with a reduced peak flow, and the expiratory rise time is increased with lower peak flows (Fig. 2). This results in reduced cough volume acceleration, a gradual loss of adequate cough flow spikes, and lower CPF values. ${ }^{68}$

Furthermore, the larynx might not be able to respond appropriately to the external airway pressures that are applied during noninvasive ventilation (NIV) ${ }^{69-75}$ In a case report from 1991, Delguste et al $^{70}$ reported complete upperairway obstruction with NIV-induced hypocapnia in 3 of 4 examined subjects treated with long-term NIV. The authors suggested that the NIV-induced hyperventilation increased upper airway resistance. ${ }^{70}$ Jounieaux et al $^{72}$ documented progressive glottic narrowing with NIV in healthy awake subjects, particularly in the absence of diaphragmatic activity. This increased inspiratory resistance and thereby reduced the fraction of air delivered to the lungs. ${ }^{72}$ This situation was aggravated during stable sleep, and even more so during deep sleep. ${ }^{71}$ Georges et al ${ }^{73}$ observed immediate obstruction from the tongue base during NIV in subjects with ALS. The most frequent solution was to reduce upper airway collapsibility by increasing the expiratory positive airway pressure to high levels; however, this was not always effective. Studies in lambs support these findings, indicating increased activity of laryngeal adduction muscles during NIV. ${ }^{76}$ Oppersma et $\mathrm{al}^{77}$ examined glottic patency during NIV in individuals with COPD and reported findings in apparent conflict with earlier studies. ${ }^{69-74}$ Oppersma et $\mathrm{al}^{77}$ noted that 


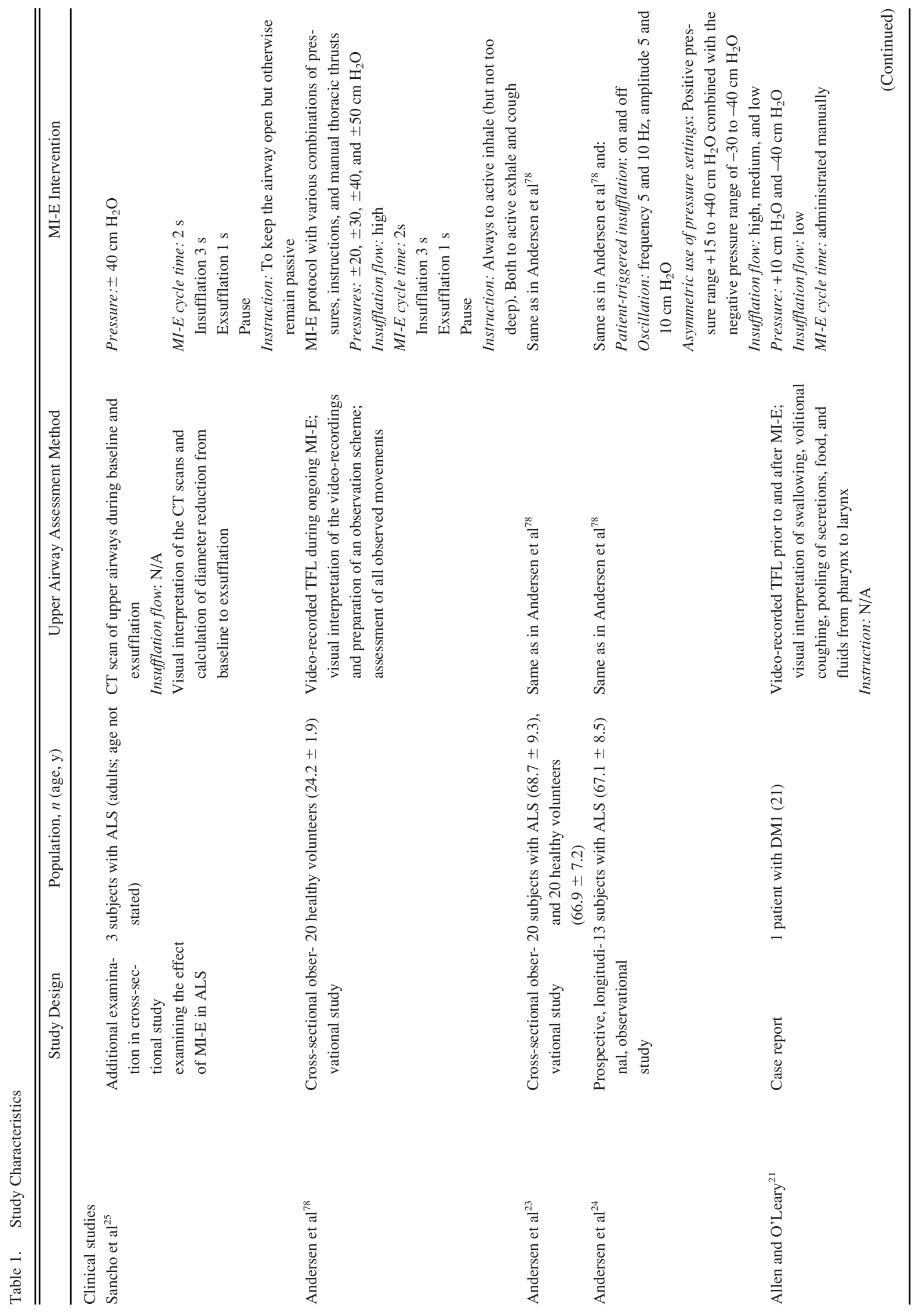




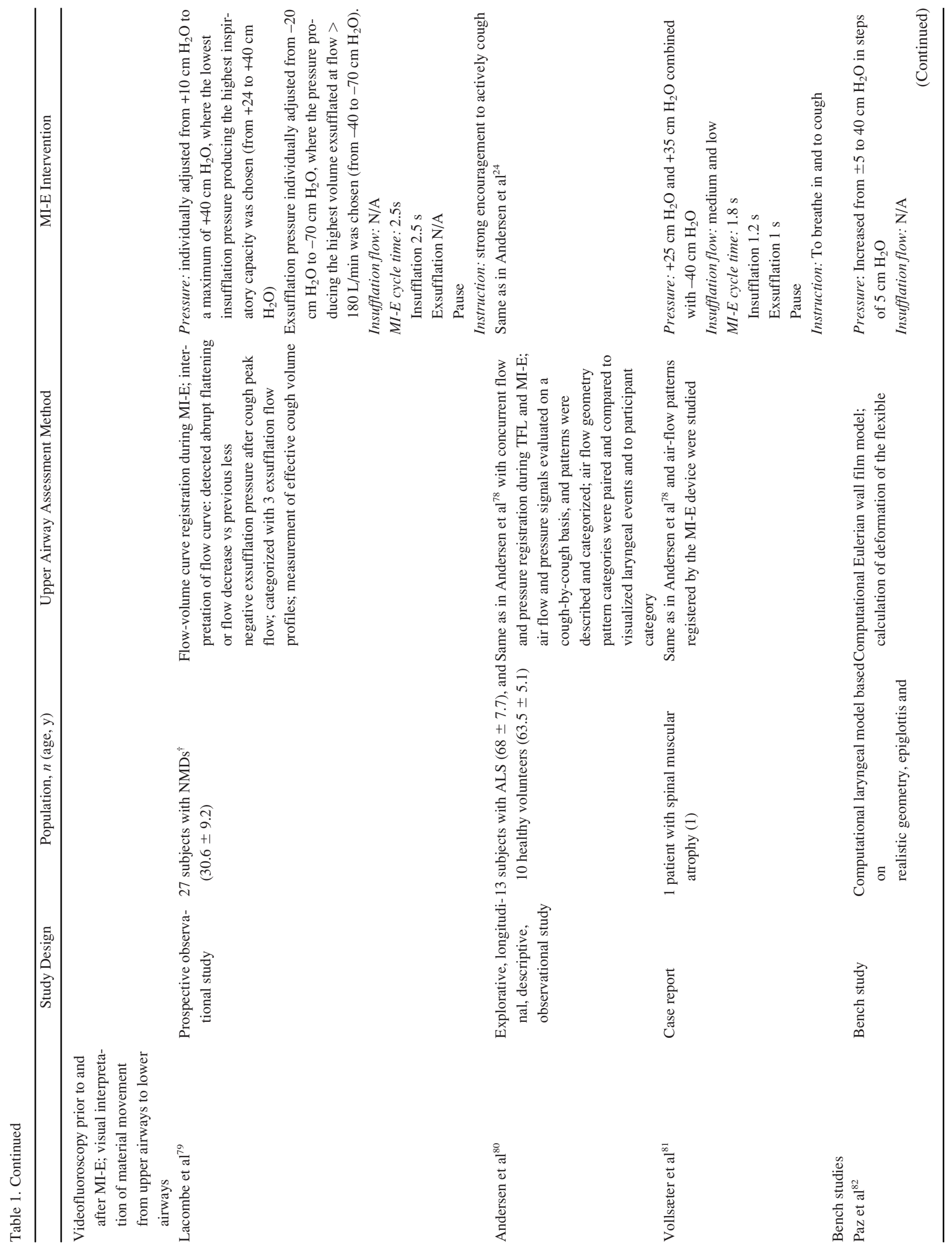




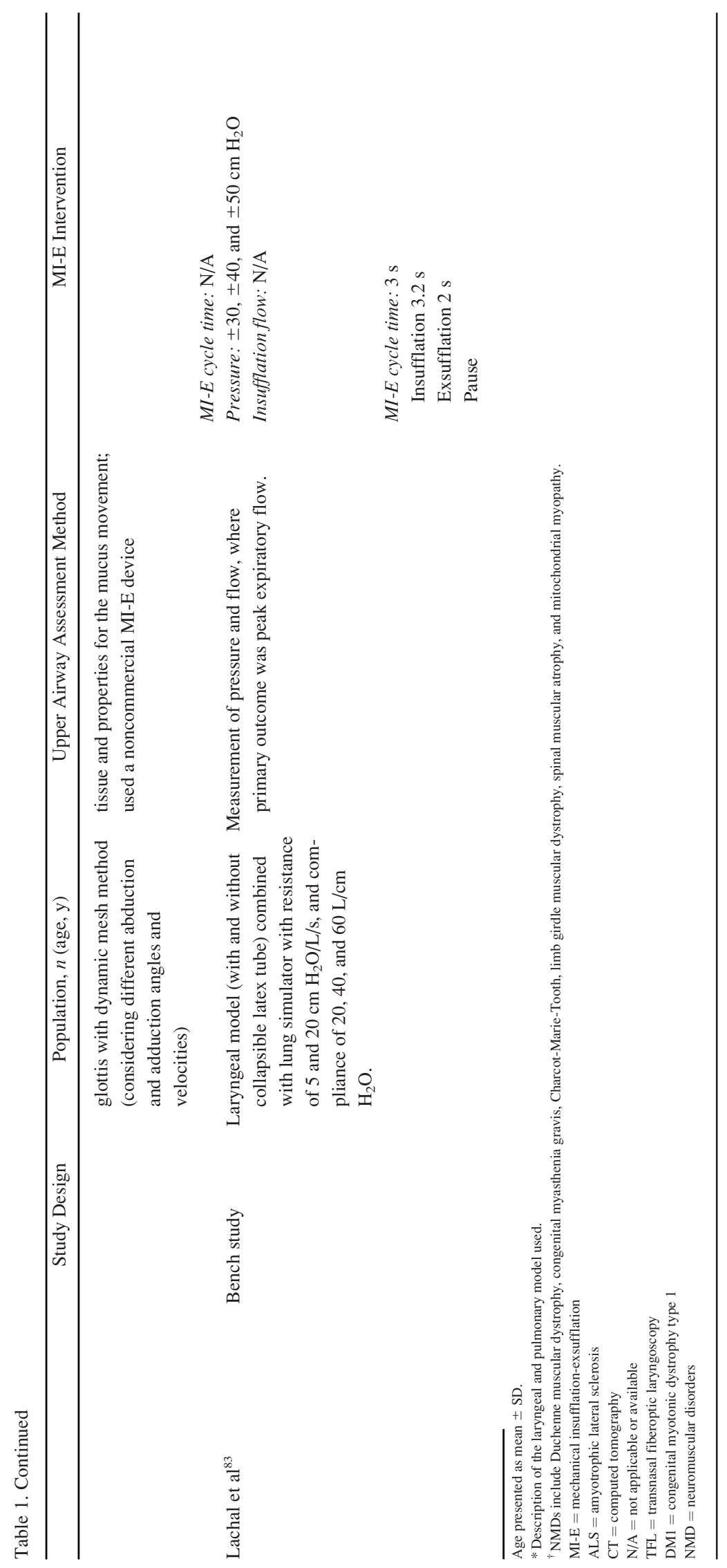




\section{UpPer Airway Assessment During Mechanically Assisted Cough}

neither the inspiratory pressure level nor the inspiratory flow pattern affected glottic patency in subjects with COPD. The authors postulated that this could be due to reflex pathways in patients with COPD being different from those in healthy individuals due to chronic exposure to $\mathrm{CO}_{2}$ or to the effects of tobacco smoking that harmed their receptors' response to chemical stimuli. ${ }^{77}$

Laryngeal function is complex as it carefully modulates and safeguards the entrance to the airway tree and serves several vitally important functions. We are far from understanding the complex interplays of all laryngeal functions, both in health and disease.

\section{Literature Review}

We searched for literature on assessment and interpretation of upper airway responses to MI-E. The review is based on repeated searches of the MEDLINE database (accessed through PubMed) using the terms (with synonyms) "mechanical insufflation-exsufflation" and "upper airway responses," focusing on studies including either clinical outcomes or laryngeal models. Studies describing either the methods used to assess the upper airways in combination with MI-E or the upper airway responses to MI-E were of interest. Furthermore, we reviewed reference lists of relevant studies. Papers written in English were considered. Studies are presented mainly in chronological order, subcategorized by the examination method used. Ten studies addressing both the assessment and findings were identified (Table 1). Additionally, some studies discussed the role of the glottic closure and opening in the MI-E therapy without assessing it.

As one of the first researchers to set focus on upper airway responses during MI-E therapy, Bach introduced the term "exsufflation-associated airway narrowing or collapse during MI-E treatment" in 1993, assuming that this phenomenon disturbed MI-E treatment efficacy in subjects with reduced upper airway control. ${ }^{6}$ Air flow curve detection, computerized tomography (CT) scanning, and transnasal fiberoptic laryngoscopy (TFL) have been applied to assess the upper airways during MI-E therapy, and bench testing with laryngeal models has been performed. One case report included the use of videofluoroscopy prior to and after the use of MI-E. ${ }^{21}$ To our knowledge, one review on upper airway function and responses to MI-E and NIV, focusing alone on TFL as the mode of examination, has been published. ${ }^{84}$

\section{CT Scanning}

Sancho et $\mathrm{al}^{25}$ were pioneers in systematically examining cough efficacy in subjects with ALS. In 2004, they examined the effect of MI-E in subjects with non-bulbar and bulbar ALS. MI-E generated clinically effective CPF in stable subjects, but not in those with bulbar dysfunction or with maximum insufflation capacity $<1 \mathrm{~L}$ and $\mathrm{CPF}<160$ $\mathrm{L} / \mathrm{min} .{ }^{25}$ Similar to Bach's postulation, ${ }^{6}$ they proposed severe upper airway collapse during exsufflation. Three subjects with ALS were studied with the user of upper airway (pharynx and oropharynx) CT scans at baseline and during exsufflation. Failure to increase $\mathrm{CPF}$ adequately was associated with dynamic collapse of the upper airway during exsufflation. The investigators suggested that coordinated glottic movements and intact bulbar function are key elements for MI-E efficacy. ${ }^{25}$

\section{TFL}

Andersen et $\mathrm{a}^{78}$ introduced dynamic TFL during MI-E (Fig. 3, Fig. 4) as a method in 2013, describing laryngeal response patterns to MI-E in healthy volunteers comparable to those described in normal cough. Healthy subjects initially abducted the glottis during both insufflation and exsufflation and displayed coordinated glottic closure when instructed to cough. When instructed to exhale during exsufflation, the glottis stayed open in the majority of subjects. However, subsequent to an initial abduction, various obstructing laryngeal movements were observed during insufflation, such as adduction of the vocal folds, retroflex movement of the epiglottis, and backward movement of the tongue base, as well as hypopharyngeal constriction during exsufflation (Table 2). The researchers advocated that MIE should not be thought of as a device that simply "fills and empties" the lungs. ${ }^{78}$

In 2017, Andersen's group published a cross-sectional study of laryngeal response patterns to MI-E in subjects with ALS and healthy controls. ${ }^{23}$ Supraglottic structures (ie, aryepiglottic folds) adducted in subjects with ALS and bulbar symptoms, especially during insufflation with high pressures (Table 2, Response B), response patterns that clearly contrasted the inspiratory abduction observed in subjects with non-bulbar ALS and healthy controls. The authors suggested these responses might explain failure of MI-E treatment in persons with bulbar ALS, as the compromised laryngeal inlet obstructs inspiratory air flow during the initial phase of cough. The study also revealed that subjects with ALS without bulbar symptoms did not always coordinate their laryngeal movements during MI-E cycles. In all subjects with ALS (with or without bulbar symptoms), short initial abduction of true vocal folds was followed by subsequent adduction during insufflation and exsufflation (Table 2, Response A). Backward movement of the tongue base was prominent (Table 2, Response D), and hypopharyngeal constriction during exsufflation (Table 2 , Response E) was observed in all (a supplemental video is available at http://www.rcjournal.com). ${ }^{23}$

In 2018, the same group ${ }^{24}$ described laryngeal response patterns to MI-E with disease progression, following 


\section{UpPer Airway Assessment During Mechanically Assisted Cough}

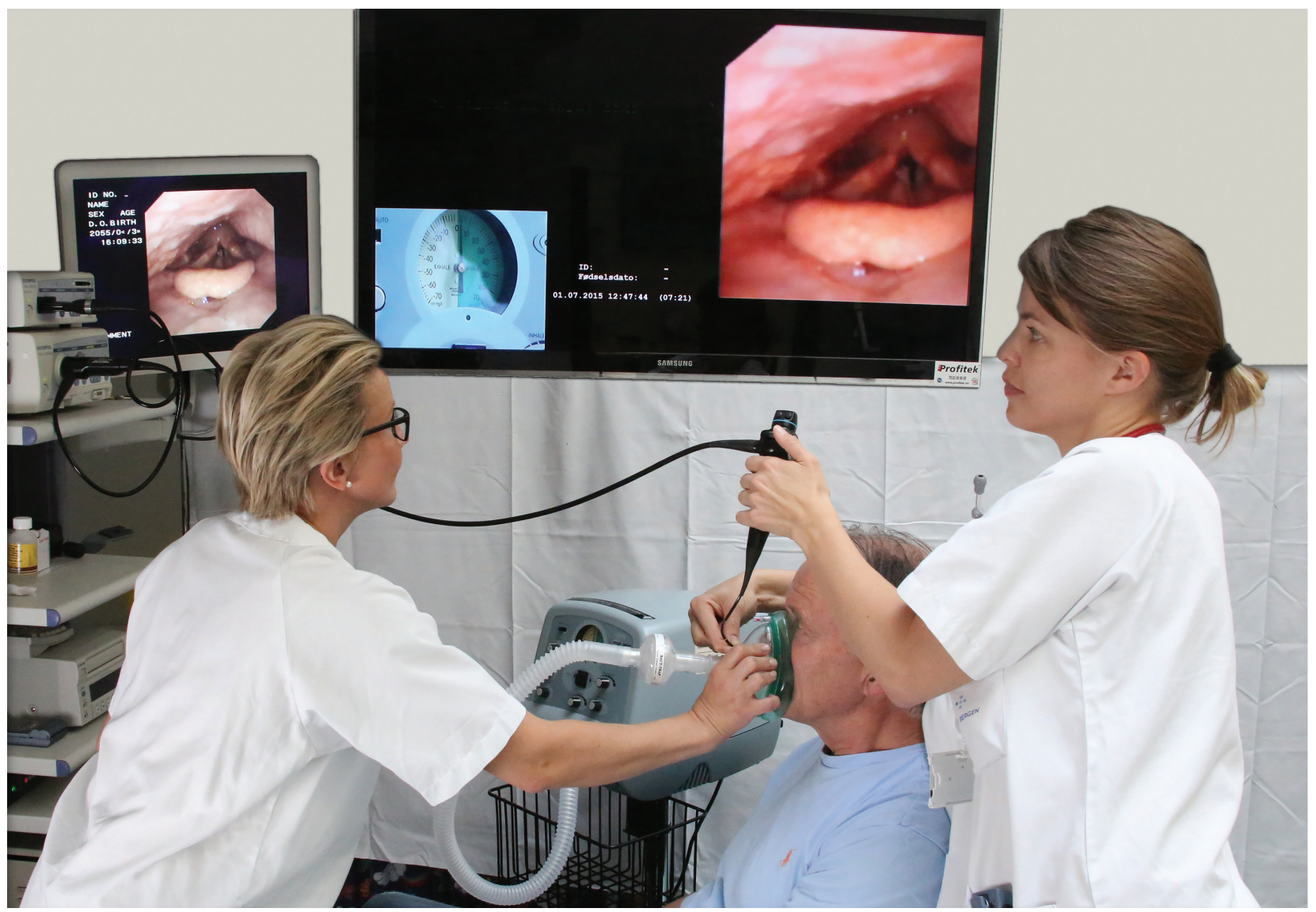

Fig. 3. A laryngoscope passing through a modified mechanical insufflation-exsufflation (MI-E) interface with the laryngoscope supported and adjusted manually. Examination visualized on the screen: 2 continuously running video recordings with the endoscopic video from the transnasal fiberoptic laryngoscopy (right) and an external video camera to the control panel of the MI-E device (left), documenting the phases of insufflation and exsufflation from the device manometer. Situation arranged. From Reference 23, with permission.

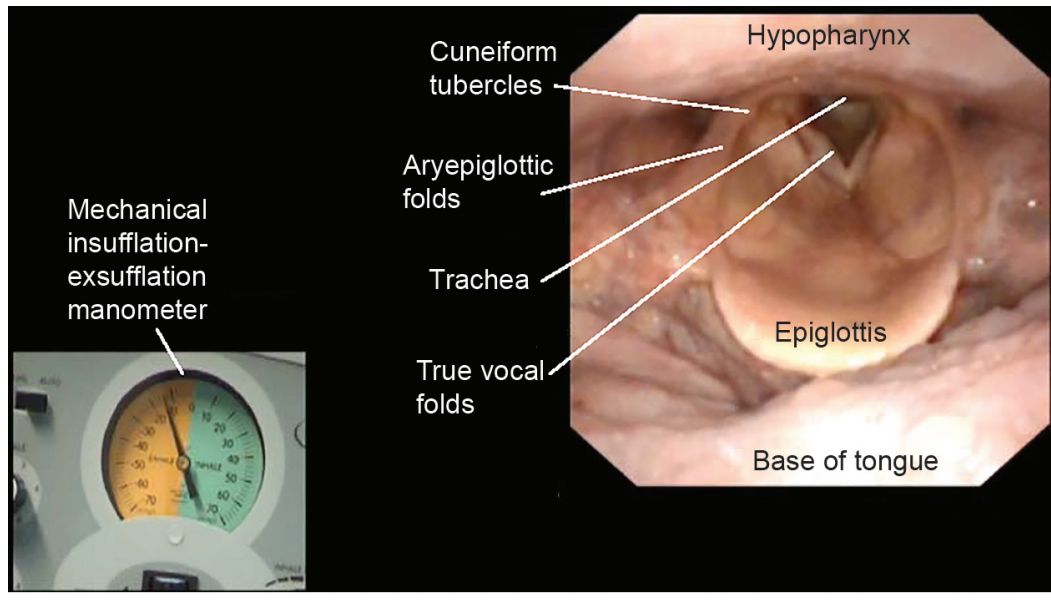

Fig. 4. The transnasal fiberoptic laryngoscopy examinations were recorded using 2 continuously running and synchronized video streams on a single screen, with the laryngeal view depicted at the right and the various phases on the mechanical insufflation-exsufflation device depicted at the left. Anatomic landmarks are illustrated on the laryngeal view. From Reference 23, with permission. 


\section{Upper Airway Assessment During Mechanically Assisted Cough}

Table 2. Five Adverse Laryngeal Events and Typical Bulbar Features*

\begin{tabular}{|c|c|c|c|c|}
\hline \multirow{2}{*}{ Response } & \multicolumn{2}{|c|}{ Laryngeal Level } & \multicolumn{2}{|l|}{ Adverse Laryngeal Response During MI-E } \\
\hline & Glottic & True vocal folds & $\begin{array}{l}\text { Adduction of true vocal folds during insufflation, paradoxical move- } \\
\text { ment of true vocal folds during inhalation creating either a slim } \\
\text { glottic opening or a total glottic closure }\end{array}$ & $\boldsymbol{\nabla}$ \\
\hline B & Supraglottic & Aryepiglottic folds & $\begin{array}{l}\text { Medial rotation of the cuneiform tubercles accompanied by consid- } \\
\text { erable adduction of the aryepiglottic folds during insufflation, to } \\
\text { the extent that it prevents observation of the glottic laryngeal } \\
\text { level below }\end{array}$ & \\
\hline $\mathrm{C}$ & & Epiglottis & $\begin{array}{l}\text { A retroflex movement of the epiglottis (a passive dorsal rotation) } \\
\text { covering the glottis, either as a brief movement or lasting } \\
\text { throughout the insufflation }\end{array}$ & $\bar{\nabla}$ \\
\hline $\mathrm{D}$ & Hypopharyngeal & Tongue base & $\begin{array}{l}\text { Backward movement of the tongue base during insufflation con- } \\
\text { stricting the laryngeal entrance }\end{array}$ & \\
\hline $\mathrm{E}$ & & Hypopharynx & A severe hypopharyngeal narrowing during exsufflation & \\
\hline
\end{tabular}
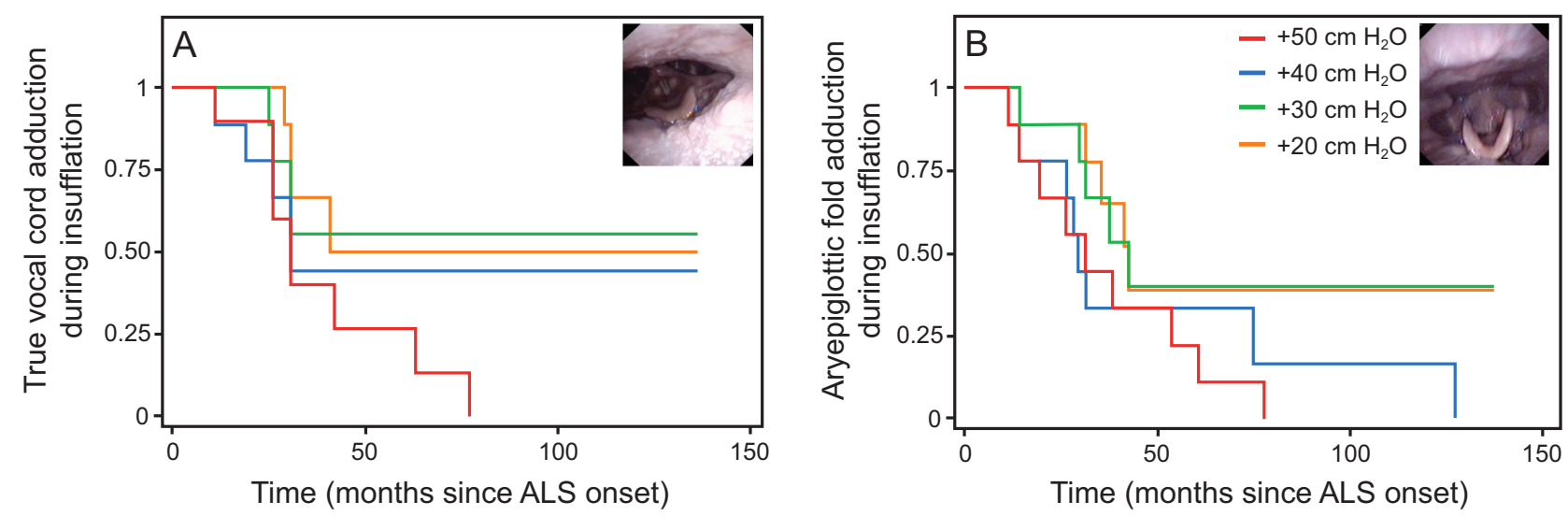

Fig. 5. Kaplan-Meier survivor function for events of adduction during mechanical insufflation-exsufflation insufflation of $(A)$ true vocal folds in spinal onset ALS $(n=9)$ and (B) aryepiglottic folds in all subjects $(n=13)$, at pressures of $50,40,30$, and $20 \mathrm{~cm} \mathrm{H}_{2} \mathrm{O}$. The $y$ axis depicts fraction of group without the event in question, and the $x$ axis months since ALS onset. ALS = amyotrophic lateral sclerosis. From Reference 24.

subjects with ALS for up to $5 \mathrm{y}$. The first signs of laryngeal adduction (aryepiglottic fold adduction, Table 2, Response B) occurred with the highest insufflation pressures and prior to any clinically evident signs of bulbar involvement (Fig. 5). Cough became less expulsive and was paralleled by laryngeal adduction occurring also at lower insufflation 

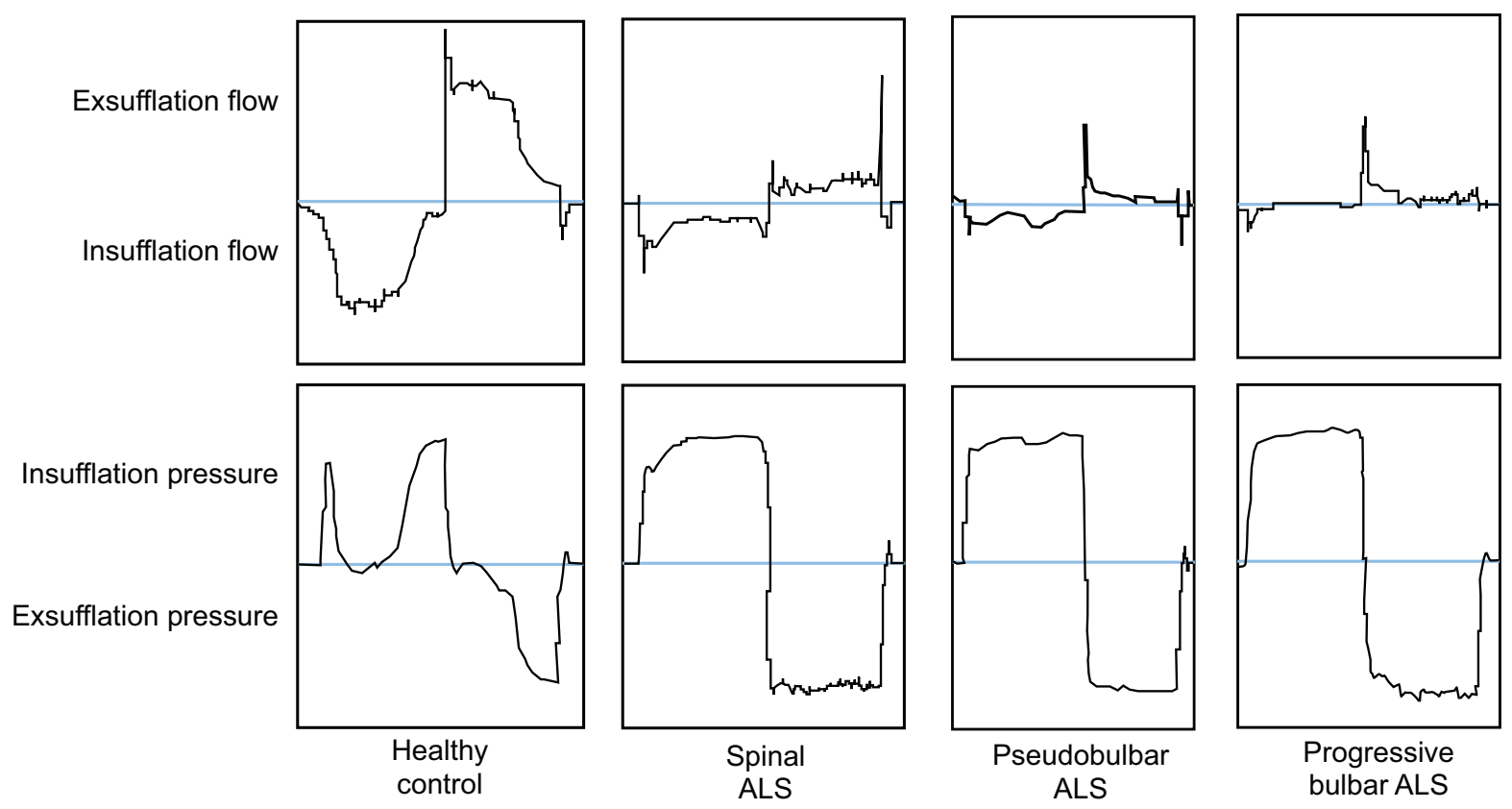

Spinal

ALS

Pseudobulbar

ALS

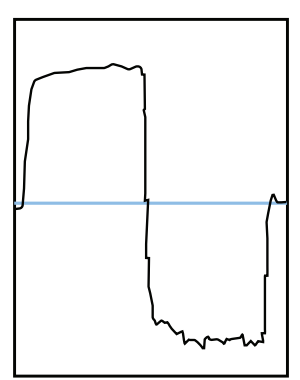

Progressive bulbar ALS

Fig. 6. Four MI-E air flow geometry patterns that were associated with being healthy and the ALS subtypes. ALS = amyotrophic lateral sclerosis. From Reference 80, with permission.

pressures. Backward movement of the tongue base (Table 2, Response D) appeared in most, and retroflex movement of the epiglottis (Table 2, Response C) was observed in half of the cases. Hypopharyngeal constriction during exsufflation (Table 2, Response E) was observed in all subjects, but later in the disease progression than adverse events during insufflation. Triggering of swallowing reflexes by the positive MI-E pressure further complicated these matters. Customized use of MI-E, with lower insufflation pressures and flows and patient-triggered insufflations, led to less laryngeal adduction. This prolonged the time for which the treatment was perceived to be efficient by subjects with ALS, thus facilitating elongated successful use of MI-E. ${ }^{24}$

The laryngeal role with respiratory therapies in children has been less studied but nonetheless is equally important. Vollsæter et al ${ }^{81}$ described a 12-month-old spinal muscular atrophy type I case with periodic problems with the MI-E device, including difficulties inflating the chest and mobilizing secretions. TFL during ongoing MI-E revealed signs of aspiration as well as laryngeal closure during insufflation in response to high inspiratory pressures, thus indicating bulbar effect, in line with clinical observations. This is similar to what was previously observed in adult subjects with ALS..$^{23,24}$ The examination with TFL was well tolerated, and the findings led to immediate and targeted adjustments of the MI-E. ${ }^{81}$

\section{TFL and Videofluoroscopy}

Allen and O'Leary ${ }^{21}$ described a case with myotonic dystrophy type 1 with dysphagia and cough failure, aiming to shed light on secretion retention in the upper airways and how use of MI-E affects this. Three hospital admissions were registered following MI-E treatment initiation. TFL and videofluoroscopy prior to and after MI-E treatment were performed, revealing food and drink material entering the lower airways. The authors argued that implementation of MI-E without exploring dysphagia and bulbar impairment may have caused recurrent aspiration and persistence of the subjects' respiratory symptoms. ${ }^{21}$

\section{Air Flow Curve Registration}

Air flow curve registration during spontaneous breathing is used widely to diagnose sleep-apnea. ${ }^{85,86}$ As lung insufflation and exsufflation require an adequately sized laryngeal inlet, ${ }^{37}$ one may assume that visually observed laryngeal adduction causes air flow obstruction, influencing treatment efficacy. ${ }^{9,10,56,79}$ Elaborating on Bach's postulation of exsufflation being the main challenge, Lacombe et $\mathrm{al}^{79}$ analyzed exsufflation air flow curves from subjects with NMDs. Following CPF, they described an abrupt flattening of the curve (ie, a flow decrease during exsufflation), assumed to indicate upper airway collapse. They introduced the parameter of effective cough volume, defined as the volume exhaled above CPF $>180 \mathrm{~L} / \mathrm{min}$. Even though the upper airways were not directly observed, the authors postulated that low effective cough volume indicates upper airway collapse with $100 \%$ sensitivity and specificity. It was suggested that using CPF alone failed to detect upper airway collapse during negative 

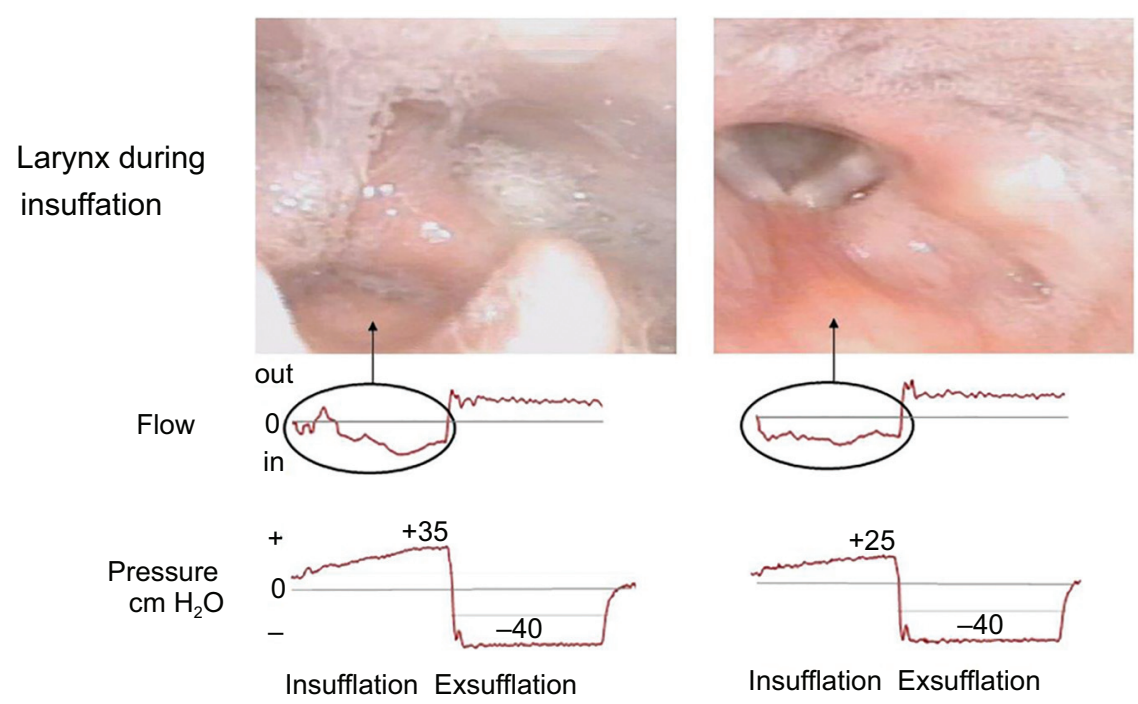

Fig. 7. Depicted flow and pressure curves from the mechanical insufflation-exsufflation with high inspiratory pressures $\left(35 \mathrm{~cm} \mathrm{H}_{2} \mathrm{O}\right)$ when the larynx closes at inspiration (left), and at lower inspiratory pressures $\left(25 \mathrm{~cm} \mathrm{H}_{2} \mathrm{O}\right.$ ) when the larynx stays open during inspiration (right). From Reference 81, with permission.

pressure titration in MI-E, and that studying the complete exsufflation air flow curve, not just the peak value, could reveal laryngeal opening or closure. ${ }^{79}$

When comparing flow curves and visualized laryngeal events during MI-E, preliminary findings from Andersen et $\mathrm{al}^{80}$ indicated that efforts to cough or exhale during exsufflation affect flow curve geometry (shape). The authors were unable to link visualized laryngeal response characteristics to unique air flow geometry patterns, but recognized several MI-E air flow geometry patterns (Fig. 6). ${ }^{80}$ Vollsæter et al ${ }^{81}$ studied air-flow and pressure patterns registered by the MI-E device following the examination with TFL during ongoing MI-E (Figure 7). Air-flow patterns registered by the MI-E device revealed altered insufflation flow geometry with the initial settings, improving after modifying the flow and pressure. ${ }^{23,24}$

\section{Laryngeal Models}

Physical and mathematical models may simplify the complex structures of the human larynx. Paz and coworkers $^{82}$ used an advanced computational model of the upper airways, the "Eulerian wall film model," which is based on realistic upper airway geometry including epiglottis, glottis, and vocal fold movements resembling those of a healthy human. An MI-E device was used to reduce mucus thickness in the upper airways (Fig. 8). The results indicated that viscous shear force was the main mechanism clearing secretions, and neither glottic closure time nor epiglottic position had significant effect. The cough efficiency was almost unaffected by the time of laryngeal adduction as long as the inspiration phase was sufficiently effective. The MI-E device improved viscous shear force, and the enhancement rate grew logarithmically with the operating pressure. $^{82}$

Lachal et $\mathrm{al}^{83}$ used a lung simulator with several resistance-compliance models and a latex tube to mimic laryngeal collapsibility. They simulated various respiratory conditions to explore the role played by the upper airways while using MI-E. Contrary to what was expected, CPF was higher with the collapsible tube. The generation of peak expiratory flow occurred within the first $100 \mathrm{~ms}$ of exsufflation, leading the authors to hypothesize that flexible tube walls accelerate the flow increase during exsufflation. ${ }^{83}$

\section{Discussion}

\section{Summary of the Findings}

In this narrative review, we focus on methods to assess upper airways during MI-E therapy and summarize the current state of the art of responses. The interpretation of findings and the following recommendations are based on the available literature as well as the authors' personal experiences. Enhancing the success rate of MI-E and NIV is of major clinical importance to vulnerable patient groups with devastating diseases, but our knowledge of upper airway responses to respiratory therapy is still limited. Due to the nature of diseases like ALS, clinical studies include small populations. Direct observations with TFL indicate that laryngeal function is highly important to the efficacy of MI-E treatment. Laryngeal bench models have shortcomings in imitating the complex and dynamic nature of the 

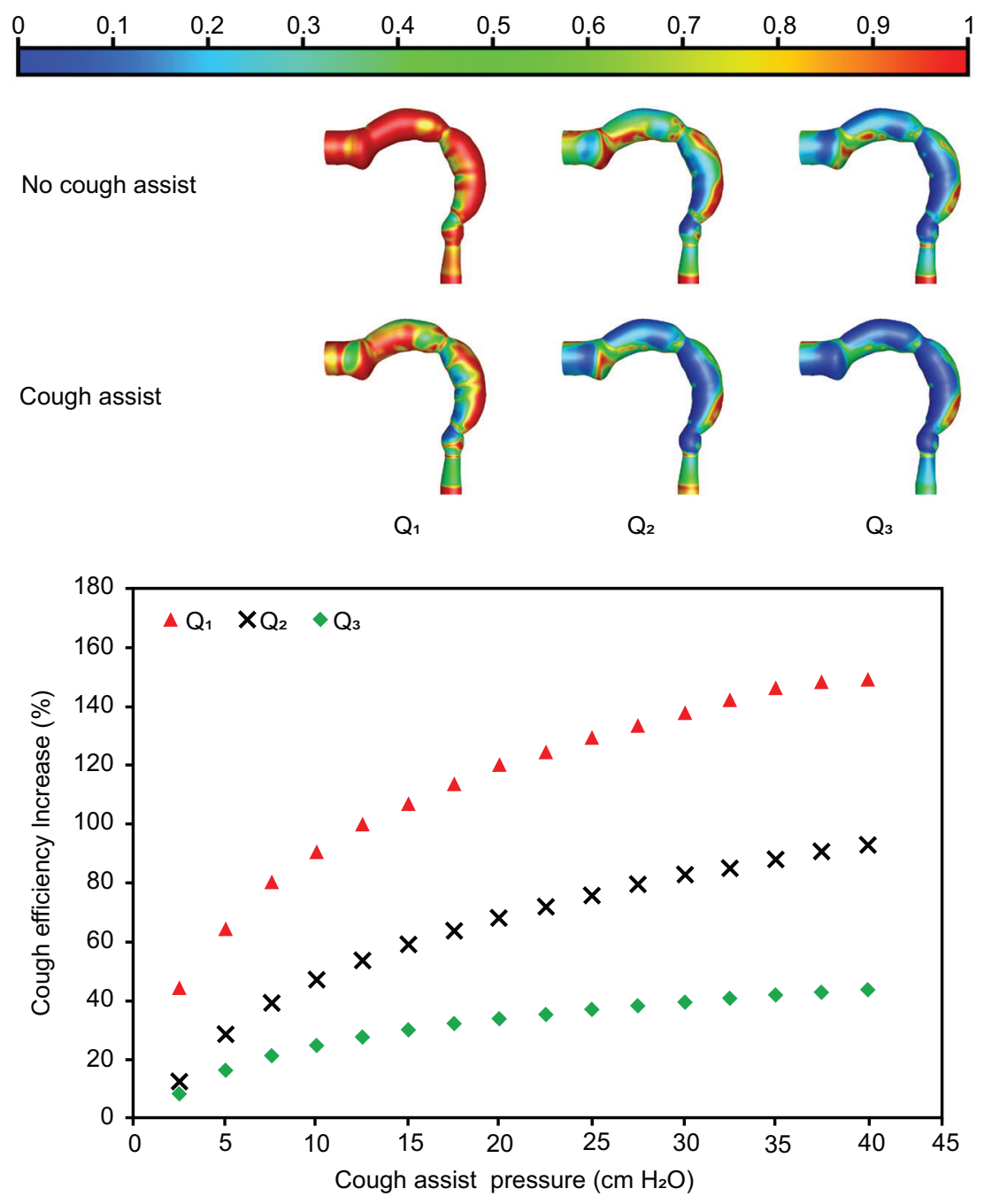

Fig. 8. Effect of mechanical insufflation-exsufflation (MI-E) device on cough efficacy. Top: The improvement of the mucus thickness contours after use of MI-E. Bottom: Cough efficiency increase at different operating pressures. The first (Q1), second (Q2), and third (Q3) quartiles of healthy people cough values are compared with and without the use of MI-E. From Reference 82, with permission.

upper airway, but they may enhance our understanding of air flow dynamics, and a wide range of MI-E settings may be systematically applied to suggest possible combinations to be used in patients. ${ }^{52,87}$

The dogma that upper airway collapse during exsufflation causes MI-E treatment failure influenced former evaluation methods that assessed the exsufflation phase alone. The CT scans by Sancho et $\mathrm{al}^{25}$ and the flow-curve shapes by Lacombe et $\mathrm{al}^{79}$ confirmed Bach's postulate that exsufflation caused upper airway collapse in subjects with bulbar dysfunction. ${ }^{6}$ Later studies indicated that this exsufflationrelated hypopharyngeal narrowing occurs also in healthy individuals. ${ }^{23,78}$ A certain degree of narrowing is beneficial, increasing linear air flow velocity and shear forces to move secretions proximally. ${ }^{1,2}$ However, the studies by Bach, ${ }^{6}$ Sancho et al, ${ }^{25}$ and Lacombe et al ${ }^{56,79}$ have been essential in introducing the vital understanding that MI-E air flows and pressures delivered via the upper airways may cause structural responses. In studies where the larynx was visualized during the whole MI-E cycle, adduction of laryngeal structures during insufflation was revealed in subjects with bulbar ALS, the opposite of the findings in healthy controls and in subjects without bulbar involvement. ${ }^{23,24} \mathrm{~A}$ compromised laryngeal inlet during insufflation will obstruct inspiratory air flow and lead to reduced filling of the lungs during the first phase of cough. This again will compromise the expiratory cough phase, conceivably creating a vacuum in the upper airways during exsufflation that leads to inefficient MI-E. ${ }^{23,24}$ This line of thinking turns the picture around in that the observed exsufflation challenges might be a consequence of laryngeal inspiratory closure rather than the cause of treatment failure.

The air flow passing through the laryngeal lumen must obey simple physical laws; when air flow or turbulence 


\section{UpPer Airway Assessment During Mechanically Assisted Cough}

Table 3. Aspects to Guide Laryngeal Evaluation With Dynamic TFL During MI-E

\begin{tabular}{|c|c|}
\hline Evaluation & Response \\
\hline Assess the drooling/pooling of secretions. How does the therapy affect this? & Retention/aspiration of saliva and/or secretions \\
\hline Is the laryngeal response to MI-E normal? & Yes/No \\
\hline $\begin{array}{l}\text { In case of abnormal laryngeal responses, determine the location of the } \\
\text { counterproductive response. }\end{array}$ & $\begin{array}{l}\text { Hypopharynx, epiglottis, base of the tongue, aryepiglottic folds, true } \\
\text { vocal folds }\end{array}$ \\
\hline Describe the abnormal response/movement. & Abduction, adduction: constriction or collapse \\
\hline $\begin{array}{l}\text { Detect the phase of the MI-E cycle in which the counterproductive } \\
\text { response appears. }\end{array}$ & Insufflation, pressure drop, exsufflation \\
\hline Detect the onset of the counterproductive event. & Immediately/During \\
\hline Identify the frequency of the counterproductive events. & In all the cycles or in some cycles \\
\hline Examine the response to altered therapy. & $\begin{array}{l}\text { Fine-tune insufflation settings (ensure triggering on every insuffla- } \\
\text { tion, decrease inspiratory flow, decrease inspiratory pressure, } \\
\text { increase inspiratory time) }\end{array}$ \\
\hline \multicolumn{2}{|l|}{ Other adjustments (describe) } \\
\hline $\begin{array}{l}\text { TFL }=\text { transnasal fiberoptic laryngoscopy } \\
\text { MI-E }=\text { mechanical insufflation-exsufflation }\end{array}$ & \\
\hline
\end{tabular}

exceeds a critical value, the pressure within the structure that confines the air flow must decrease, and deformations of that structure will eventually occur. Structural deformation subsequently affects air flow, a situation labeled "flowstructure interactions" by physicists. ${ }^{88}$ In the human larynx, reflex mechanisms as well as voluntarily controlled neuromuscular interactions add complexity to this model. MI-E pressures may provoke disadvantageous laryngeal movements, and the supraglottic area seems most prone to collapse. $^{23,24}$ Therapeutic use of positive pressure provokes laryngeal narrowing. ${ }^{69-75}$ Thus, it is not surprising that positive insufflation pressures during MI-E promote laryngeal closure in individuals with ALS. ${ }^{23,24}$ ALS affects motor neurons in the brain and spinal cord. Both afferent and efferent innervation may play a part, laryngeal reflex circuits may be hypo- responsive or hyper-responsive or dysregulated, ${ }^{89-91}$ and loss of motor control and strength, spasticity, and sensory insufficiency in the laryngeal muscles further reduce laryngeal control. ${ }^{89,92,93}$ Inefficacy of MI-E treatment is multifactorial and varies with each patient. This research field is still in an embryonic phase, and further assessment of upper airway responses during the complete MI-E cycle is crucial to understand these complex interactions. We acknowledge and certainly encourage future research in this field.

\section{Where Should We Go From Here?}

TFL was previously a specialized tool used in otolaryngology clinics. It is presently used in several functional contexts (eg, during swallowing, ${ }^{94}$ inspiratory muscle training, ${ }^{95}$ exercise tests ${ }^{96,97}$ ) performed by medical doctors, speech therapists, and other trained health professionals. Sayas Catalàn et $\mathrm{al}^{74}$ postulated that NIV titration by TFL led to fewer obstructive events in subjects with upper airway obstruction. The knowledge of upper airway responses during MI-E in the pediatric population is scarce and should be targeted. One clinical case report ${ }^{81}$ and our clinical experience with individual cases support the notion that TFL is feasible and tolerated in small children as well, especially in those familiar with airway suction through the nose. In preterm infants with dysphagia, simultaneous videofluoroscopy and TFL in evaluation of swallowing is feasible and has higher diagnostic yield than each procedure done separately. ${ }^{98}$

We believe that TFL performed during ongoing noninvasive respiratory therapies improves our understanding of laryngeal responses and aids in tailoring optimal patient treatment (Table 3). However, TFL examination during MI-E has limitations. It is an invasive procedure that requires a skilled provider and may be judged unpleasant. During MI-E maneuvers, the larynx tends to move upward, requiring adjustments of the laryngoscope's position. Anatomical structures may preclude visual access, such as a high standing epiglottis or a narrow hypopharynx. Supraglottic adduction by nature obscures the view of the glottis. Airway secretions may also obscure the view, so pretreatment to clear secretions should be considered. To produce adequate recordings, several MI-E cycles may be required.

Alternatives to TFL should be explored. CT scanning applies ionizing radiation, is expensive, is stationary, and is hardly dynamic. Simple throat auscultation may provide information of laryngeal air flow and synchronization of glottic closure to MI-E cycles, similar to cervical auscultation used to evaluate swallowing. ${ }^{99}$ Ultrasound imaging may visualize laryngeal structures, ${ }^{100}$ and a study of laryngeal responses during MI-E and NIV combining both TFL and 


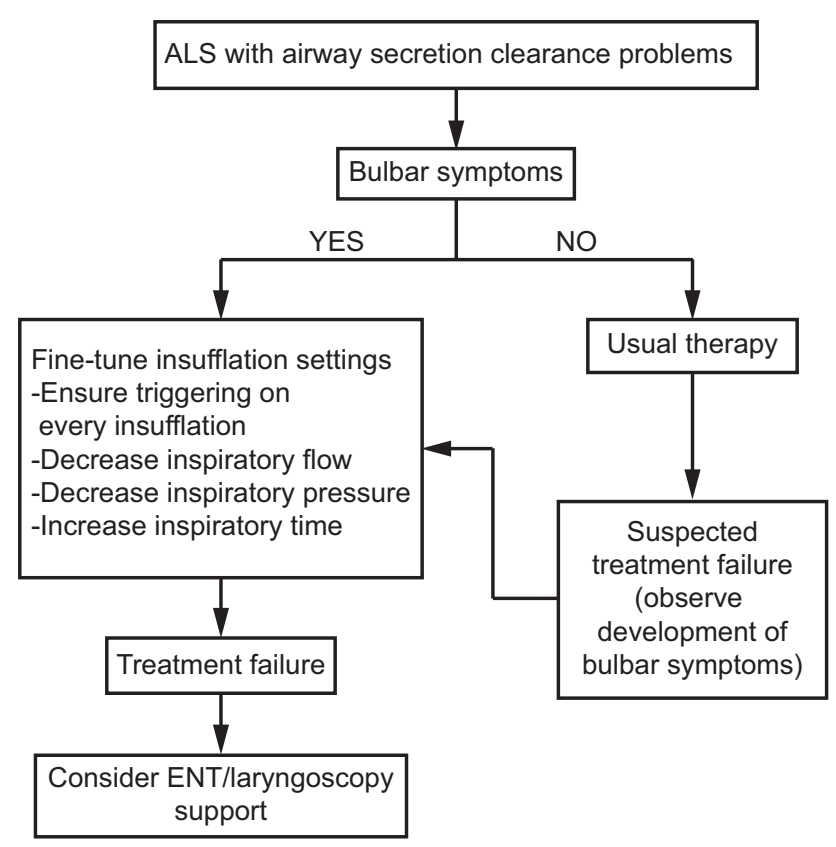

Fig. 9. A practical algorithm suggesting how to adjust the settings of mechanical insufflation-exsufflation when used to treat individuals with amyotrophic lateral sclerosis for airway secretion clearance problems. ENT = ear-nose-throat physician. From Reference 23, with permission.

ultrasound is planned to explore the validity of ultrasound as a diagnostic tool in this context (ClinicalTrials.gov registration NCT04586855).

To what extent laryngeal adduction observed during MI-E influences the expiratory air flow velocity, which is crucial to move secretions, represents an important functional issue. ${ }^{2}$ Simultaneous monitoring of air flow curves and laryngeal movements during MI-E could reveal more information. Potential mask leaks, and the fact that the relationship between the structural responses in the upper airways and the air flow shapes still remains poorly understood, may interfere.

\section{Clinical Implications}

As alluded to by Simonds, ${ }^{101}$ individuals with poor laryngeal control may not have failed their MI-E therapy, rather the therapy may in fact have failed them. It is reasonable to assume that when the MI-E cycles are in synchrony with the upper airway responses, this will improve the success rate of MI-E.

\section{Individualizing MI-E Treatment}

MI-E use should be customized for the individual with counterproductive upper airway responses (Figure 9). Generally, the inspiratory air flow should not enter the upper airways too abruptly. High inspiratory pressures may generate laryngeal closure, so pressures should be gently titrated upward. Asymmetric settings with lower positive insufflation pressure than the corresponding negative exsufflation pressure used in the same respiratory cycle may be combined with lower insufflation flows. Increasing inspiratory time may be necessary to achieve the required insufflation volume prior to exsufflation. ${ }^{23,87,102}$ A prolonged inspiration seems to be physiological in inducing cough. ${ }^{68}$ It may be challenging or impossible for individuals with bulbar dysfunction to handle several rapid MI-E cycles. Successful treatment requires that the larynx is "reset" after exsufflation, and swallowing or closing reflexes should be brought to an end before the next insufflation. An increased time interval between exsufflation and insufflation, or the use of one cough cycle at a time, might be appropriate to prepare the larynx for the next insufflation. ${ }^{24}$ Dynamic TFL during ongoing MI-E could be a valuable and well-tolerated tool to further optimize treatment, providing direct anatomical views and potential aspiration tendency, as well as feedback on treatment responses. $^{23,24,103}$ It will be important to perform further studies to provide a variety of subjects with the best possible treatment titrated in the most precise way.

\section{Effect Outcomes for Airway Clearance}

The important questions are whether individually optimized MI-E treatment will assist airway secretion clearance in individuals with poor laryngeal control, and how to measure this assistance. Efficient laryngeal closure and opening are linked to $\mathrm{CPF},{ }^{56}$ hence individuals with poor laryngeal control fail to create a prominent peak expiratory flow. ${ }^{68}$ We should consider whether CPF is an appropriate effect outcome measure for airway clearance in those with poor laryngeal control.

The findings of Andersen et $\mathrm{al}^{24}$ emphasize the importance of keeping the larynx open to achieve a sufficient insufflation volume prior to cough and to allow both volume and flow acceleration to move the secretions. Simulations with advanced laryngeal models indicate that MI-E can achieve effective shear forces even with a fixed glottic opening, but glottic closure and opening significantly improves this. ${ }^{82}$ Volpe et al ${ }^{104}$ emphasized the importance of expiratory flow bias on secretion movement, indicating that the relation and difference of peak insufflation and exsufflation flows influence upstream secretion movement. Expiratory flow bias and MI-E pressure gradients correlated significantly with mucus displacement, whereas CPF did not. ${ }^{104}$ In addition to keeping laryngeal structures open, ${ }^{23}$ lower insufflation flows might increase expiratory flow bias and, consequently, the efficacy of clearing secretions. ${ }^{104,105}$ The CPF phase accounts for only $25 \%$ of the cough shearing force, and the sustained flow that occurs after this is probably of great significance. ${ }^{106}$ Lacombe's group suggested there is a volume-dependent factor of effective cough volume that may detect upper- 


\section{UpPer Airway Assessment During Mechanically Assisted Cough}

airway obstruction, ${ }^{79}$ and they also suggested a time-dependent efficacy factor during exsufflation, defined as effective cough time (ie, the duration that $\mathrm{CPF}>180 \mathrm{~L} / \mathrm{min}$ ). ${ }^{56}$

To conclude, judging MI-E efficacy is complex. ${ }^{57}$ The key element is that the upper airways must allow air to flow in and out of the lungs. Measurements of flow bias, cough velocity, effective cough time, and cough volume and assessment of upper airway structural responses will add further clinically important information. One should aim at always optimizing and tailoring MI-E settings individually in each person. In the long run, treatment compliance and quality of life, as well as rates of infections, exacerbations, and hospitalizations, should be studied.

\section{Summary}

The larynx is a highly complex organ that carefully modulates and safeguards the airway entrance. In individuals with poor laryngeal control, therapeutic positive pressures may provoke disadvantageous laryngeal responses, precluding the lungs from filling with air and compromising attempts to assist the expiratory phase of cough. This leads to inefficient MI-E therapy and discomfort. Great care must be taken to avoid applying pressures and cough cycles that the larynx is unable to handle. Video-recorded TFL is feasible to characterize laryngeal responses throughout MI-E and NIV interventions. Individually adjusted settings may prevent adduction of laryngeal structures during insufflation and thus may prolong successful use of MI-E and, possibly, NIV. In our opinion, direct laryngeal visualization during treatment is currently the best and most objective approach in the most challenging patients.

\section{REFERENCES}

1. Fink JB. Forced expiratory technique, directed cough, and autogenic drainage. Respir Care 2007;52(9):1210-1221.

2. Lawson TV, Harris RS. Assessment of the mechanical efficiency of coughing in healthy young adults. Clin Sci 1967;33(1):209-224.

3. Toussaint M, Chatwin M, Gonzales J, Berlowitz DJ, ENMC Respiratory Therapy Consortium. 228th ENMC International Workshop: airway clearance techniques in neuromuscular disorders. Naarden, The Netherlands, 3-5 Mar, 2017. Neuromuscul Disord 2018;28(3):289-298.

4. Barach AL, Beck GJ. Exsufflation with negative pressure; physiologic and clinical studies in poliomyelitis, bronchial asthma, pulmonary emphysema, and bronchiectasis. AMA Arch Intern Med 1954;93(6):825-841.

5. Miske LJ, Hickey EM, Kolb SM, Weiner DJ, Panitch HB. Use of the mechanical in-exsufflator in pediatric patients with neuromuscular disease and impaired cough. Chest 2004;125(4):1406-1412.

6. Bach JR. Mechanical insufflation-exsufflation: comparison of peak expiratory flows with manually assisted and unassisted coughing techniques. Chest 1993;104(5):1553-1562.

7. Barach AL. The application of pressure, including exsufflation, in pulmonary emphysema. Am J Surg 1955;89(2):372-382

8. Williams EK, Holaday DA. The use of exsufflation with negative pressure in postoperative patients. Am J Surg 1955;90(4):637-640.
9. Fauroux B, Guillemot N, Aubertin G, Nathan N, Labit A, Clement A, Lofaso F. Physiologic benefits of mechanical insufflation-exsufflation in children with neuromuscular diseases. Chest $2008 ; 133$ (1):161-168.

10. Chatwin M, Ross E, Hart N, Nickol AH, Polkey MI, Simonds AK. Cough augmentation with mechanical insufflation/exsufflation in patients with neuromuscular weakness. Eur Respir J 2003;21(3):502-508.

11. Gomez-Merino E, Bach JR. Duchenne muscular dystrophy: prolongation of life by noninvasive ventilation and mechanically assisted coughing. Am J Phys Med Rehabil 2002;81(6):411-415.

12. Chatwin M, Bush A, Simonds AK. Outcome of goal-directed noninvasive ventilation and mechanical insufflation/exsufflation in spinal muscular atrophy type I. Arch Dis Child 2011;96(5):426-432.

13. Chen TH, Liang WC, Chen IC, Liu YC, Hsu JH, Jong YJ. Combined noninvasive ventilation and mechanical insufflator-exsufflator for acute respiratory failure in patients with neuromuscular disease: effectiveness and outcome predictors. Ther Adv Respir Dis 2019; 13:1753466619875928.

14. Terzi N, Guerin C, Gonçalves MR. What's new in management and clearing of airway secretions in ICU patients? It is time to focus on cough augmentation. Intensive Care Med 2019;45(6):865-868.

15. Gonçalves MR, Honrado T, Winck JC, Paiva JA. Effects of mechanical insufflation-exsufflation in preventing respiratory failure after extubation: a randomized controlled trial. Crit Care 2012;16(2):R48.

16. Rose L, Adhikari NK, Leasa D, Fergusson DA, McKim D. Cough augmentation techniques for extubation or weaning critically ill patients from mechanical ventilation. Cochrane Database Syst Rev 2017;1:CD011833.

17. Siriwat R, Deerojanawong J, Sritippayawan S, Hantragool S, Cheanprapai P. Mechanical insufflation-exsufflation versus conventional chest physiotherapy in children with cerebral palsy. Respir Care 2018;63(2):187-193.

18. He YL, Liao D, Kang H, Ke C, Chen Y, Liu S, et al. Comparison of mechanical insufflation-exsufflation and percussors in the treatment of lung infections for children with cerebral palsy. J Pediatr Resp Dis 2013;9:40-47.

19. Chatwin M, Simonds AK. Long-term mechanical insufflation-exsufflation cough assistance in neuromuscular disease: patterns of use and lessons for application. Respir Care 2020;65(2):135-143.

20. Hov B, Andersen T, Toussaint M, Vollsæter M, Mikalsen IB, Indrekvam S, et al. Prevalence of long-term mechanical insufflationexsufflation in children with neurological conditions: a populationbased study. Dev Med Child Neurol 2021;63(5):537-544.

21. Allen JE, O'Leary EL. Considerations for chest clearance and cough augmentation in severe bulbar dysfunction: a case study. Can J Respir Ther 2018;54(3):66-70.

22. Pradat PF, Bernard E, Corcia P, Couratier P, Jublanc C, Querin G, et al. The French national protocol for Kennedy's disease (SBMA): consensus diagnostic and management recommendations. Orphanet J Rare Dis 2020;15(1):90.

23. Andersen T, Sandnes A, Brekka AK, Hilland M, Clemm H, Fondenes $\mathrm{O}$, et al. Laryngeal response patterns influence the efficacy of mechanical assisted cough in amyotrophic lateral sclerosis. Thorax 2017;72(3):221-229.

24. Andersen TM, Sandnes A, Fondenes O, Nilsen RM, Tysnes OB, Heimdal $\mathrm{JH}$, et al. Laryngeal responses to mechanically assisted cough in progressing amyotrophic lateral sclerosis. Respir Care 2018;63(5):538-549.

25. Sancho J, Servera E, Díaz J, Marín J. Efficacy of mechanical insufflation-exsufflation in medically stable patients with amyotrophic lateral sclerosis. Chest 2004;125(4): 1400-1405.

26. Mustfa N, Aiello M, Lyall RA, Nikoletou D, Olivieri D, Leigh PN, et al. Cough augmentation in amyotrophic lateral sclerosis. Neurology 2003;61(9):1285-1287. 


\section{UpPer Airway Assessment During Mechanically Assisted Cough}

27. Rafiq MK, Bradburn M, Proctor AR, Billings CG, Bianchi S, McDermott CJ, et al. A preliminary randomized trial of the mechanical insufflator-exsufflator versus breath-stacking technique in patients with amyotrophic lateral sclerosis. Amyotroph Lateral Scler Frontotemporal Degener 2015;16(7-8):448-455.

28. Bach JR. Amyotrophic lateral sclerosis: predictors for prolongation of life by noninvasive respiratory aids. Arch Phys Med Rehabil 1995;76(9):828-832.

29. Hanayama K, Ishikawa Y, Bach JR. Amyotrophic lateral sclerosis: successful treatment of mucous plugging by mechanical insufflationexsufflation. Am J Phys Med Rehabil 1997;76(4):338-339.

30. Physiology and phylogeny of the larynx and trachea. In: Sandhu GS, Reza Nouraei SA, editors. Laryngeal and tracheobronchial stenosis. San Diego: Plural Publishing; 2016:27-40.

31. Hull JH, Backer V, Gibson PG, Fowler SJ. Laryngeal dysfunction: assessment and management for the clinician. Am J Respir Crit Care Med 2016;194(9):1062-1072.

32. Stein JF. Why did language develop? Int J Pediatr Otorhinolaryngol 2003;67(Suppl 1):S131-S135.

33. Ferris BG Jr, Mead J, Opie LH. Partitioning of respiratory flow resistance in man. J Appl Physiol 1964;19:653-658.

34. Bartlett D, Jr. Respiratory functions of the larynx. Physiol Rev 1989;69(1):33-57.

35. Baier H, Wanner A, Zarzecki S, Sackner MA. Relationships among glottis opening, respiratory flow, and upper airway resistance in humans. J Appl Physiol Respir Environ Exerc Physiol 1977;43 (4):603-611.

36. Darwin C, Bynum WF. The origin of species by means of natural selection: the preservation of favored races in the struggle for life. New York: AL Burt; 2009.

37. Pierce RJ, Worsnop CJ. Upper airway function and dysfunction in respiration. Clin Exp Pharmacol Physiol 1999;26(1):1-10.

38. Ludlow CL. Laryngeal reflexes: physiology, technique, and clinical use. J Clin Neurophysiol 2015;32(4):284-293.

39. Hadjikoutis S, Wiles CM. Respiratory complications related to bulbar dysfunction in motor neuron disease. Acta Neurol Scand 2001;103 (4):207-213.

40. Petcu LG, Sasaki CT. Laryngeal anatomy and physiology. Clin Chest Med 1991;12(3):415-423.

41. Brancatisano T, Collett PW, Engel LA. Respiratory movements of the vocal cords. J Appl Physiol Respir Environ Exerc Physiol 1983;54(5):1269-1276.

42. England SJ, Bartlett D Jr, Daubenspeck JA. Influence of human vocal cord movements on airflow and resistance during eupnea. J Appl Physiol Respir Environ Exerc Physiol 1982;52(3):773-779.

43. Kuna ST, Vanoye CR. Laryngeal response during forced vital capacity maneuvers in normal adult humans. Am J Respir Crit Care Med 1994;150(3):729-734.

44. Brancatisano TP, Dodd DS, Engel LA. Respiratory activity of posterior cricoarytenoid muscle and vocal cords in humans. J Appl Physiol Respir Environ Exerc Physiol 1984;57(4):1143-1149.

45. Prudon B, Birring SS, Vara DD, Hall AP, Thompson JP, Pavord ID. Cough and glottic-stop reflex sensitivity in health and disease. Chest 2005;127(2):550-557.

46. Bhabu P, Poletto C, Mann E, Bielamowicz S, Ludlow CL. Thyroarytenoid muscle responses to air pressure stimulation of the laryngeal mucosa in humans. Ann Otol Rhinol Laryngol 2003;112 (10):834-840

47. Theurer JA, Bihari F, Barr AM, Martin RE. Oropharyngeal stimulation with air-pulse trains increases swallowing frequency in healthy adults. Dysphagia 2005;20(4):254-260.

48. Leith DE. The development of cough. Am Rev Respir Dis 1985;131 (5):S39-42.
49. McCool FD, Leith DE. Pathophysiology of cough. Clin Chest Med 1987;8(2):189-195.

50. Chatwin M. Mechanical aids for secretion clearance. Int J Respir Care 2009;5(2):50-53.

51. Feinstein AJ, Zhang Z, Chhetri DK, Long J. Measurement of cough aerodynamics in healthy adults. Ann Otol Rhinol Laryngol 2017;126 (5):396-400

52. Hoffman Ruddy B, Nadun Kuruppumullage D, Carnaby G, Crary M, Lehman J, Ilegbusi OJ. Computational modelling of cough function and airway penetrant behavior in patients with disorders of laryngeal function. Laryngoscope Investig Otolaryngol 2017;2(1):23-29.

53. Bach JR, Saporito LR. Criteria for extubation and tracheostomy tube removal for patients with ventilatory failure: a different approach to weaning. Chest 1996;110(6):1566-1571.

54. Sancho J, Servera E, Bañuls P, Marín J. Effectiveness of assisted and unassisted cough capacity in amyotrophic lateral sclerosis patients. Amyotroph Lateral Scler Frontotemporal Degener 2017;18(7-8):498-504.

55. Chatwin M, Toussaint M, Gonçalves MR, Sheers N, Mellies U, Gonzales-Bermejo J, et al. Airway clearance techniques in neuromuscular disorders: a state of the art review. Respir Med 2018;136:98-110.

56. Lacombe M, Del Amo Castrillo L, Bore A, Chapeau D, Horvat E, Vaugier I, et al. Comparison of three cough-augmentation techniques in neuromuscular patients: mechanical insufflation combined with manually assisted cough, insufflation-exsufflation alone and insufflation-exsufflation combined with manually assisted cough. Respiration 2014;88(3):215-222.

57. Branson RD, Benditt JO. Optimizing mechanical insufflation-exsufflation - much more than cough peak flow. Respir Care 2020;65 (2):265-268

58. Barach AL, Beck G, Smith W. Mechanical production of expiratory flow rates surpassing the capacity of human coughing. Trans Assoc Am Physicians 1953;66:315-324.

59. Shinn JR, Kimura KS, Campbell BR, Sun LA, Wootten CT, Garrett $\mathrm{CG}$, et al. Incidence and outcomes of acute laryngeal injury after prolonged mechanical ventilation. Crit Care Med 2019;47(12):1699-1706.

60. Woodson G. Management of neurologic disorders of the larynx. Ann Otol Rhinol Laryngol 2008;117(5):317-326.

61. García-Pachón E, Martí J, Mayos M, Casan P, Sanchis J. Clinical significance of upper airway dysfunction in motor neurone disease. Thorax 1994;49(9):896-900

62. Tomik J, Tomik B, Partyka D, Skladzien J, Szczudlik A. Profile of laryngological abnormalities in patients with amyotrophic lateral sclerosis. J Laryngol Otol 2007;121(11):1064-1069.

63. Hillel A, Dray T, Miller R, Yorkston K, Konikow N, Strande E, et al. Presentation of ALS to the otolaryngologist/head and neck surgeon: getting to the neurologist. Neurology 1999;53(8 Suppl 5):S22-25.discussion S35-26.

64. Roth CR, Glaze LE, Goding GS Jr, David WS. Spasmodic dysphonia symptoms as initial presentation of amyotrophic lateral sclerosis. J Voice 1996;10(4):362-367.

65. Yiu Y, Curtis JA, Perry SE, Troche MS. Relationship of vocal fold atrophy to swallowing safety and cough function in Parkinson's disease. Laryngoscope 2020;130(2):303-308.

66. van den Engel-Hoek L, Erasmus CE, van Hulst KC, Arvedson JC, de Groot IJ, de Swart BJ. Children with central and peripheral neurologic disorders have distinguishable patterns of dysphagia on videofluoroscopic swallow study. J Child Neurol 2014;29(5):646-653.

67. Boel L, Pernet K, Toussaint M, Ides K, Leemans G, Haan J, et al. Respiratory morbidity in children with cerebral palsy: an overview. Dev Med Child Neurol 2019;61(6):646-653.

68. Tabor-Gray LC, Gallestagui A, Vasilopoulos T, Plowman EK. Characteristics of impaired voluntary cough function in individuals with amyotrophic lateral sclerosis. Amyotroph Lateral Scler Frontotemporal Degener 2019;20(1-2):37-42 


\section{UpPer Airway Assessment During Mechanically Assisted Cough}

69. Kuna ST, McCarthy MP, Smickley JS. Laryngeal response to passively induced hypocapnia during NREM sleep in normal adult humans. J Appl Physiol (1985) 1993;75(3):1088-1096.

70. Delguste P, Aubert-Tulkens G, Rodenstein DO. Upper airway obstruction during nasal intermittent positive-pressure hyperventilation in sleep. Lancet 1991;338(8778):1295-1297.

71. Jounieaux V, Aubert G, Dury M, Delguste P, Rodenstein DO. Effects of nasal positive-pressure hyperventilation on the glottis in normal sleeping subjects. J Appl Physiol (1985) 1995;79(1):186-193.

72. Jounieaux V, Aubert G, Dury M, Delguste P, Rodenstein DO. Effects of nasal positive-pressure hyperventilation on the glottis in normal awake subjects. J Appl Physiol (1985) 1995;79(1):176-185.

73. Georges M, Attali V, Golmard JL, Morélot-Panzini C, CrevierBuchman L, Collet JM, et al. Reduced survival in patients with ALS with upper airway obstructive events on non-invasive ventilation. J Neurol Neurosurg Psychiatry 2016;87(10):1045-1050.

74. Sayas Catalán J, Jiménez Huerta I, Benavides Mañas P, Luján M, López-Padilla D, Arias Arias E, et al. Videolaryngoscopy with noninvasive ventilation in subjects with upper-airway obstruction. Respir Care 2017;62(2):222-230.

75. Parreira VF, Jounieaux V, Aubert G, Dury M, Delguste PE, Rodenstein DO. Nasal two-level positive-pressure ventilation in normal subjects: effects of the glottis and ventilation. Am J Respir Crit Care Med 1996;153(5):1616-1623.

76. Moreau-Bussière F, Samson N, St-Hilaire M, Reix P, Lafond JR, Nsegbe E, et al. Laryngeal response to nasal ventilation in nonsedated newborn lambs. J Appl Physiol (1985) 2007;102(6):2149-2157.

77. Oppersma E, Doorduin J, Gooskens PJ, Roesthuis LH, van der Heijden E, van der Hoeven JG, et al. Glottic patency during noninvasive ventilation in patients with chronic obstructive pulmonary disease. Respir Physiol Neurobiol 2019;259:53-57.

78. Andersen T, Sandnes A, Hilland M, Halvorsen T, Fondenes O, Heimdal JH, et al. Laryngeal response patterns to mechanical insufflation-exsufflation in healthy subjects. Am J Phys Med Rehabil 2013;92(10):920-929.

79. Lacombe M, Boré A, Amo Castrillo LD, Boussaïd G, Falaize L, Vlachos E, et al. Peak cough flow fails to detect upper airway collapse during negative pressure titration for cough-assist. Arch Phys Med Rehabil 2019;100(12):2346-2353.

80. Andersen T, Hov B, Fondenes O, Clemm H, Halvorsen T, Drange Røksund $\mathrm{O}$, et al. Laryngeal responses and airflow geometry in ALS during mechanically assisted cough. Eur Resp J 2020;56(Suppl 64):1271.

81. Vollsæter M, Skjoldmo A, Røksund OD, Hilland M, Andersen T. Tailoring NIV by dynamic laryngoscopy in a child with spinal muscular atrophy type I. Clin Case Rep 2021. doi: CrossRef.

82. Paz C, Suárez E, Parga O, Vence J. Glottis effects on the cough clearance process simulated with a CFD dynamic mesh and Eulerian wall film model. Comput Methods Biomech Biomed Engin 2017;20 (12):1326-1338.

83. Lachal R, Louis B, Subtil F, Guérin C. Bench assessment of the effect of a collapsible tube on the efficiency of a mechanical insufflationexsufflation device. Respir Care 2019;64(7):752-759.

84. Conde B, Martins N, Brandão M, Pimenta AC, Winck JC. Upper airway video endoscopy: assessment of the response to positive pressure ventilation and mechanical in-exsufflation. Pulmonology 2019;25 (5):299-304.

85. Atkeson AD, RoyChoudhury A, Harrington-Moroney G, Shah B, Mitsumoto H, Basner RC. Patient-ventilator asynchrony with nocturnal noninvasive ventilation in ALS. Neurology 2011;77(6):549-555.

86. Bloch KE. Polysomnography: a systematic review. Technol Health Care 1997;5(4):285-305
87. Hov B, Andersen T, Toussaint M, Fondenes O, Carlsen KCL, Hovland V. Optimizing expiratory flows during mechanical cough in a pediatric neuromuscular lung model. Pediatr Pulmonol 2020;55(2):433-440.

88. Tu J, Inthavong K, Ahmadi G. Computational fluid and particle dynamics in the human respiratory system. Netherlands: Springer; 2013.

89. Ruoppolo G, Onesti E, Gori MC, Schettino I, Frasca V, Biasiotta A, et al. Laryngeal sensitivity in patients with amyotrophic lateral sclerosis. Front Neurol 2016;7:212.

90. Koufman JA, Block C. Differential diagnosis of paradoxical vocal fold movement. Am J Speech Lang Pathol 2008;17(4):327-334.

91. Maschka DA, Bauman NM, McCray PB Jr, Hoffman HT, Karnell MP, Smith RJ. A classification scheme for paradoxical vocal cord motion. Laryngoscope 1997;107(11 Pt 1):1429-1435.

92. Kühnlein P, Gdynia HJ, Sperfeld AD, Lindner-Pfleghar B, Ludolph AC, Prosiegel M, et al. Diagnosis and treatment of bulbar symptoms in amyotrophic lateral sclerosis. Nat Clin Pract Neurol 2008;4 (7):366-374

93. Ertekin C, Aydogdu I, Yüceyar N, Kiylioglu N, Tarlaci S, Uludag B. Pathophysiological mechanisms of oropharyngeal dysphagia in amyotrophic lateral sclerosis. Brain 2000;123(1):125-140.

94. Langmore SE, Schatz K, Olson N. Endoscopic and videofluoroscopic evaluations of swallowing and aspiration. Ann Otol Rhinol Laryngol 1991;100(8):678-681.

95. Sandnes A, Andersen T, Hilland M, Ellingsen TA, Halvorsen T, Heimdal JH, et al. Laryngeal movements during inspiratory muscle training in healthy subjects. J Voice 2013;27(4):448-453.

96. Heimdal JH, Roksund OD, Halvorsen T, Skadberg BT, Olofsson J. Continuous laryngoscopy exercise test: a method for visualizing laryngeal dysfunction during exercise. Laryngoscope 2006;116(1):52-57.

97. Walsted ES, Swanton LL, van van Someren K, Morris TE, Furber M, Backer $\mathrm{V}$, et al. Laryngoscopy during swimming: a novel diagnostic technique to characterize swimming-induced laryngeal obstruction. Laryngoscope 2017;127(10):2298-2301.

98. Kamity R, Ferrara L, Dumpa V, Reynolds J, Islam S, Hanna N. Simultaneous videofluoroscopy and endoscopy for dysphagia evaluation in preterm infants: a pilot study. Front Pediatr 2020;8:537.

99. Marrara JL, Duca AP, Dantas RO, Trawitzki LV, Lima RA, Pereira JC. Swallowing in children with neurologic disorders: clinical and videofluoroscopic evaluations. Pro Fono 2008;20(4):231-236.

100. Fukuhara T, Donishi R, Matsuda E, Koyama S, Fujiwara K, Takeuchi H. A novel lateral approach to the assessment of vocal cord movement by ultrasonography. World J Surg 2018;42(1):130-136.

101. Simonds AK. Progress in respiratory management of bulbar complications of motor neuron disease/amyotrophic lateral sclerosis? Thorax 2017;72(3):199-201

102. Gómez-Merino E, Sancho J, Marín J, Servera E, Blasco ML, Belda FJ, et al. Mechanical insufflation-exsufflation: pressure, volume, and flow relationships and the adequacy of the manufacturer's guidelines. Am J Phys Med Rehabil 2002;81(8):579-583.

103. Andersen TM, Sandnes A, Fondenes O, Clemm H, Halvorsen T, Nilsen RM, et al. Laryngoscopy can be a valuable tool for unexpected therapeutic response in noninvasive respiratory interventions. Respir Care 2018;63(11):1459-1461.

104. Volpe MS, Naves JM, Ribeiro GG, Ruas G, Amato MBP. Airway clearance with an optimized mechanical insufflation-exsufflation maneuver. Respir Care 2018;63(10):1214-1222.

105. Volpe MS, Guimarães FS, Morais CC. Airway clearance techniques for mechanically ventilated patients: insights for optimization. Respir Care 2020;65(8): 1174-1188.

106. Harris RS, Lawson TV. The relative mechanical effectiveness and efficiency of successive voluntary coughs in healthy young adults. Clin Sci 1968;34(3):569-577. 